\title{
Detection of drug resistance in Mycobacterium tuberculosis
}

Lee W. Riley*

Editor

The report by Florea et al. (Broad-range PCR coupled with mass-spectrometry for the detection of Mycobacterium tuberculosis drug resistance, GERMS 2016) describes the use of a commercial PCR assay coupled with electrospray ionization mass spectrometry (PCR/ESI-MS) to detect isoniazid (INH) and rifampin (RIF) resistance in 63 M. tuberculosis isolates obtained from Romanian patients with pulmonary tuberculosis (TB). They compared the results of the assay to those based on the absolute drug concentration method in Löwenstein-Jensen medium. The sensitivity and specificity of the PCR/ESI-MS assay was $100 \%$ and $95 \%$ for INH resistance, while the sensitivity and specificity was $92 \%$ and 97\% for RIF resistance, respectively. The results were compared to a large-scale application of this technology used to detect drug resistance in 1340 M. tuberculosis isolates from different regions of the world reported by Massire et al. in 2010. ${ }^{1}$ This study found a sensitivity of $89.3 \%$ and $96.3 \%$, and specificity of $95.8 \%$ and $98.6 \%$ for INH and RIF, respectively, compared to the indirect proportion method in Middlebrook 7H10 medium. ${ }^{1}$

Many tests based on multiplex nucleic acid amplification of genes with mutations associated with drug resistance in $M$. tuberculosis have been

*MD, Division of Infectious Disease and Vaccinology, School of Public Health, University of California, Berkeley, USA. 1wriley@berkeley.edu

Article downloaded from www.germs.ro

Published: March 2016

(C) GERMS 2016

ISSN $2248-2997$

ISSN - L = $2248-2997$ reported over the last 20 years. $^{2-9}$ The PCR/ESIMS is yet another approach that is based on coupling multiplexed nucleic acid amplification to mass spectrometry. It was first reported in 2005 by Ecker et al., who described the use of an universal biosensor Ibis T5000 to analyze samples obtained from military recruits during respiratory disease outbreaks as part of a biodefense application. ${ }^{10}$ The process used high-performance electrospray ionization mass spectrometry and base composition analysis of PCR amplicons from a target DNA sequence (e.g., strain-specific alleles) to determine both the bacterial species and genotype of the strain from a mixed population of bacteria in clinical samples. ${ }^{10}$ Primers can be multiplexed to target multiple highly variable regions of bacterial genomes, and mass spectrometric analysis of the PCR-amplified products can then be performed to genotype bacterial strains. If the variable genes that are targeted involve mutations in genes associated with drug resistance, this approach can be used to identify resistance.

The major advantage of the PCR/ESI-MS assay is its ease in detecting resistance in $\mathrm{M}$. tuberculosis, especially resistance to INH and RIF. If resistance to both INH and RIF (defined as multidrug resistance) can be detected easily, appropriate multidrug treatment regimen can be initiated in most situations.

However, there are several limitations that restrict its practical application. The need for a multiple set of primers to genotype bacterial pathogens or identify drug resistance associated with multiple mutations for a particular group of antibiotics (e.g. mutations in $\beta$-lactamase genes) can add to the complexity and cost of this technology. Although resistance to INH and RIF in most strains of M. tuberculosis is associated with 
mutations in restricted regions within a limited set of genes ( $k a t \mathrm{G}$, inh $\mathrm{A}$, ahpC promoter gene for INH resistance, and rpoB for RIF resistance), if resistance to other drugs need to be identified (e.g., ethambutol [EMB] or fluoroquinolone [FQ]), additional primers would be required. Furthermore, M. tuberculosis gene mutations associated with resistance to other drugs (e.g., embB codon 306 with EMB resistance and gyrA with FQ resistance) are not as strongly correlated as those for INH and RIF resistance.

The positive predictive value (PPV) of all tests based on amplification of genes to detect drug resistance is affected by differences in the geographic source of the M. tuberculosis isolates tested. In this study by Florea et al., all but one of the 63 isolates belonged to the Euro-American lineage (PGG 2 and 3), a lineage in which mutations associated with INH and RIF resistance have been previously well characterized. A test for mutations conferring drug resistance on a small collection of isolates belonging to a related lineage from a geographically confined source would show high sensitivity. Another small study from the United States that applied the PCR/ESI-MS assay on 48 isolates reported a sensitivity of $100 \%$ for both INH and RIF. ${ }^{11}$ A study in China that applied the PCR/ESI-MS assay to characterize $M$. tuberculosis isolates from Shanghai (low TB endemic region) and Chongqing (high TB endemic region) found that mutations conferring drug resistance to INH and RIF were more diversified in the region of low $\mathrm{TB}$ endemicity than in the region of high TB endemicity. ${ }^{12}$ This diversity was revealed not by PCR/ESI-MS but by sequencing the target genes. ${ }^{12}$

The abovementioned study in China demonstrates that the PCR/ESI-MS assay does not have the resolution of the sequence-based information. This assay may not be able to distinguish mutations that result in no mass change, such as C-to-G or G-to-C changes. However, such potential ambiguity can be prevented by designing the primer pairs to avoid amplification of such regions.

There are other issues that preclude the practical implementation of PCR/ESI-MS, including its cost, especially for its implementation in resource-limited high-burden settings, where TB diagnosis is most needed. With a rapid M. tuberculosis drug-susceptibility test such as GeneXpert ${ }^{8}$ (which is also costly) already endorsed by WHO, the advantage of PCR/ESI-MS is not obvious. However, its use in a research setting to screen drug-resistant $M$. tuberculosis strains for further analyses (e.g., sequencing drug-resistance genes, whole genome sequencing) is one practical application of this technology.

Conflicts of interest: None to declare.

References

1. Massire C, Ivy CA, Lovari R, et al. Simultaneous identification of mycobacterial isolates to the species level and determination of tuberculosis drug resistance by PCR followed by electrospray ionization mass spectrometry. J Clin Microbiol 2011;49:908-17. [CrossRef] [PubMed] [FullText]

2. Rossau R, Traore H, De Beenhouwer H, et al. Evaluation of the INNO-LiPA Rif. TB assay, a reverse hybridization assay for the simultaneous detection of Mycobacterium tuberculosis complex and its resistance to rifampin. Antimicrob Agents Chemother 1997;41:2093-8. [PubMed] [FullText]

3. Hillemann D, Weizenegger M, Kubica T, Richter E, Niemann S. Use of the genotype MTBDR assay for rapid detection of rifampin and isoniazid resistance in Mycobacterium tuberculosis complex isolates. J Clin Microbiol 2005;43:3699-703. [CrossRef] [PubMed] [FullText]

4. Miotto P, Piana F, Cirillo DM, Migliori GB. Genotype MTBDRplus: a further step toward rapid identification of drug-resistant Mycobacterium tuberculosis. J Clin Microbiol 2008;46:393-4. [CrossRef] [PubMed] [FullText]

5. Herrera L, Jiménez S, Valverde A, García-Aranda MA, Sáez-Nieto JA. Molecular analysis of rifampicin-resistant Mycobacterium tuberculosis isolated in Spain (1996-2001). Description of new mutations in the rpoB gene and review of the literature. Int J Antimicrob Agents 2003;21:403-8. [CrossRef] [PubMed]

6. Sali M, De Maio F, Caccuri F, et al. Multicenter evaluation of Anyplex Plus MTB/NTM MDR-TB assay for 
rapid detection of Mycobacterium tuberculosis complex and multidrug-resistant isolates in pulmonary and extrapulmonary specimens. J Clin Microbiol 2016;54:59-63. [CrossRef] [PubMed]

7. Denkinger CM, Schumacher SG, Boehme CC, Dendukuri N, Pai M, Steingart KR. Xpert MTB/RIF assay for the diagnosis of extrapulmonary tuberculosis: a systematic review and meta-analysis. Eur Respir J 2014;44:435-46. [CrossRef] [PubMed]

8. Steingart KR, Schiller I, Horne DJ, Pai M, Boehme CC, Dendukuri N. Xpert ${ }^{\circledR}$ MTB/RIF assay for pulmonary tuberculosis and rifampicin resistance in adults. Cochrane Database Syst Rev 2014;1:CD009593. [CrossRef] [PubMed] [FullText]

9. Lawn SD, Nicol MP. Xpert ${ }^{\circledR}$ MTB/RIF assay: development, evaluation and implementation of a new rapid molecular diagnostic for tuberculosis and rifampicin resistance. Future Microbiol 2011;6:1067-82. [CrossRef] [PubMed] [FullText]

10. Ecker DJ, Sampath R, Blyn LB, et al. Rapid identification and strain-typing of respiratory pathogens for epidemic surveillance. Proc Natl Acad Sci U S A. 2005;102:8012-7. [CrossRef] [ubMed] [FullText]

11. Simner PJ, Buckwalter SP, Uhl JR, Wengenack NL. Identification of Mycobacterium species and Mycobacterium tuberculosis complex resistance determinants by use of PCRelectrospray ionization mass spectrometry. J Clin Microbiol 2013;51:3492-8. [CrossRef] [PubMed] [FullText]

12. Wang F, Massire $\mathrm{C}$, Li $\mathrm{H}$, et al. Molecular characterization of drug-resistant Mycobacterium tuberculosis isolates circulating in China by multilocus PCR and electrospray ionization mass spectrometry. J Clin Microbiol 2011;49:2719-21. [CrossRef] [PubMed] [FullText] 